\title{
Association of circulating insulin-like growth factor 1 and insulin-like growth factor binding protein 3 with the risk of ovarian cancer: A systematic review and meta-analysis
}

\author{
QIAO WANG, CE BIAN, HONGLING PENG, LEI HE and XIA ZHAO \\ Department of Gynecology and Obstetrics, West China Second Hospital, \\ Sichuan University, Chengdu, Sichuan 610041, P.R. China \\ Received October 16, 2014; Accepted January 8, 2015
}

DOI: $10.3892 / \mathrm{mco} .2015 .516$

\begin{abstract}
Insulin-like growth factor 1 (IGF-1) and its main binding protein (IGFBP-3) in blood have been associated with the risk of several types of cancer. However, epidemiological studies have inconsistent results regarding the association of circulating IGF-1/IGFBP-3 levels with ovarian cancer risk. A systematic review of the prospective studies was conducted using meta-analysis to evaluate the existing evidence. Pubmed and Embase databases were searched to identify the relevant studies published before May 1, 2014. Four highly qualified studies with a total of 627 cases and 1,358 controls were finally included in the meta-analysis. Random effects meta-analysis was conducted by combining study-specific odds ratios (ORs) of ovarian cancer for the highest verses lowest exposure levels. A dose-response association was further assessed by relating the $\log$ of ORs for different exposure levels. As a result, the pooled ORs for the highest verses lowest categories of IGF-1/IGFBP-3 were 0.85 [95\% confidence interval (CI), 0.51-1.40]/0.78 (95\% CI, 0.43-1.40). In the subgroup analyses, the pooled ORs of IGF-1/IGFBP-3 were 1.89 (95\% CI, 0.64-5.59)/1.08 (95\% CI, 0.50-2.32) for the subgroup with cases diagnosed at $<55$ years, and 0.74 (95\% CI, 0.50-1.08)/0.98 (95\% CI, 0.73-1.33) for the subgroup with cases diagnosed at $\geq 55$ years. No linear association between circulating IGF-1/IGFBP-3 levels and ovarian cancer risk was identified. As no significant association of IGF-1/IGFBP-3 with ovarian cancer risk was identified in the present meta-analysis of existing studies, more studies with greater quality are required in the future.
\end{abstract}

Correspondence to: Dr Xia Zhao, Department of Gynecology and Obstetrics, West China Second Hospital, Sichuan University, 37 Guo-Xue-Xiang Road, Chengdu, Sichuan 610041, P.R. China E-mail: xia-zhao@126.com; 66518456@qq.com

Key words: ovarian cancer, cancer risk, insulin-like growth factor 1, insulin-like growth factor binding protein 3

\section{Introduction}

The insulin-like growth factor (IGF) family is a complex molecular signaling pathway, which plays an important role in oncogenesis, tumor progression, metastasis and chemoresistance (1). One of the key factors in this family is IGF-1, which is an endocrine and autocrine/paracrine peptide expressed in the majority of cell types and circulating at high levels (2). More than $90 \%$ of circulating IGF-1 is bound to IGF binding protein 3 (IGFBP-3), which stabilizes IGF-1 in the blood and regulates its bioavailability (3). IGF-1 and IGFBP-3 are involved in cellular proliferation, differentiation and apoptosis, which are indicated in cancer etiology (4). Blood concentrations of IGF-1/IGFBP-3 have been associated with the risk of prostate, colorectal and premenopausal breast cancer (5-9). Certain epidemiological studies have suggested an association of circulating IGF-1/IGFBP-3 levels with ovarian cancer risk (10-12). As the results of previous studies have been inconsistent, the present review was conducted to evaluate the evidence from existing studies examining the association of circulating IGF-1/IGFBP-3 with ovarian cancer risk via meta-analysis.

\section{Materials and methods}

Search strategy. A systematic literature search of Pubmed and Embase databases was conducted to identify all the studies published before May 1, 2014, which investigated the association of circulating IGF-1 or IGFBP-3 with the ovarian cancer risk. The following keywords were used during the search: 'Insulin-like growth factor' and 'ovarian cancer'. Reference lists of relevant studies and general reviews were also searched. No restriction of languages was imposed. The systematic review was performed following the guideline of the Meta-analysis Of Observational Studies in Epidemiology (13).

Eligibility criteria. The eligibility of studies was assessed by two investigators (Q.W. and H.L.P.) independently. Studies were included into the meta-analysis when they met the following criteria: i) Cohort or case-control studies published in full texts; ii) researching the association of circulating 
IGF-1/IGFBP-3 with ovarian cancer risk; iii) categorizing circulating IGF-1/IGFBP-3 concentrations into tertile or quartile levels; and iv) reporting odds ratios (ORs) with $95 \%$ confidence intervals (CIs), with results from crude and adjusted (adjusted for confounders) models. Study quality was assessed using the nine-star Newcastle-Ottawa scale (14).

Data extraction. The two investigators mentioned performed data extraction independently and discussed the results to make a consensus. The following variables were recorded: First author's name, publication year, geographic region where the study was conducted, study period, study design, sample size, IGFs assay, categorizing and corresponding cut-points of IGF-1/IGFBP-3 levels, ORs with 95\% CIs for each category verses reference (the lowest category) of IGF-1/IGFBP-3, the numbers of cases and controls in each exposure category, and confounders considered in the adjustment models. When necessary, the primary authors were contacted for additional information.

Statistical analysis. Considering that the IGF assays and categorizing cut-points differed across studies, a random effects model (15) was conducted by combining study-specific maximally adjusted ORs for the highest verses lowest exposure levels to evaluate the association of IGF-1/IGFBP-3 with ovarian cancer risk. The pooled ORs and 95\% CIs were used to assess the strength of association. Studies reporting the exact numbers of cases and controls in each exposure level were included in the random effects dose-response meta-analysis. The method proposed by previous studies $(5,16)$ was used to calculate the linear trends by relating the log of ORs for different exposure levels.

The degree of heterogeneity among studies was assessed via $\mathrm{Q}$ and $\mathrm{I}^{2}$ statistics. Subgroup analyses and meta-regression models (17) were conducted to investigate sources of heterogeneity. Sensitivity analyses were performed to evaluate the stability of the results. To estimate the publication bias, funnel plots were used. Funnel plot asymmetry was assessed by Egger's regression test $(\mathrm{P}<0.05$ was considered to indicate a statistically significant publication bias) (18). All the analyses were repeated with unadjusted ORs.

All the statistical tests were performed with the Stata software (version 12.0; StataCorp, College Station, TX, USA). $\mathrm{P}<0.05$ was considered to indicate a statistically significant difference.

\section{Results}

Study characteristics. A flow diagram of the literature search is shown in Fig. 1. Among the 64 potentially relevant studies, four were finally included in the meta-analysis.

The remaining four studies $(10-13,19)$ were published in English between 2002 and 2007 and involved a total of 1,958 patients (627 cases and 1,358 controls). Overall, the methodology qualities of studies were satisfying, since study designs, sample sizes, exclusion criteria and diagnosis of cases were clearly demonstrated, except for the limited information of follow-up in certain studies. Of these four included case-control studies, three were nested within large prospective cohorts (10-13). The study of Peeters et al (10)

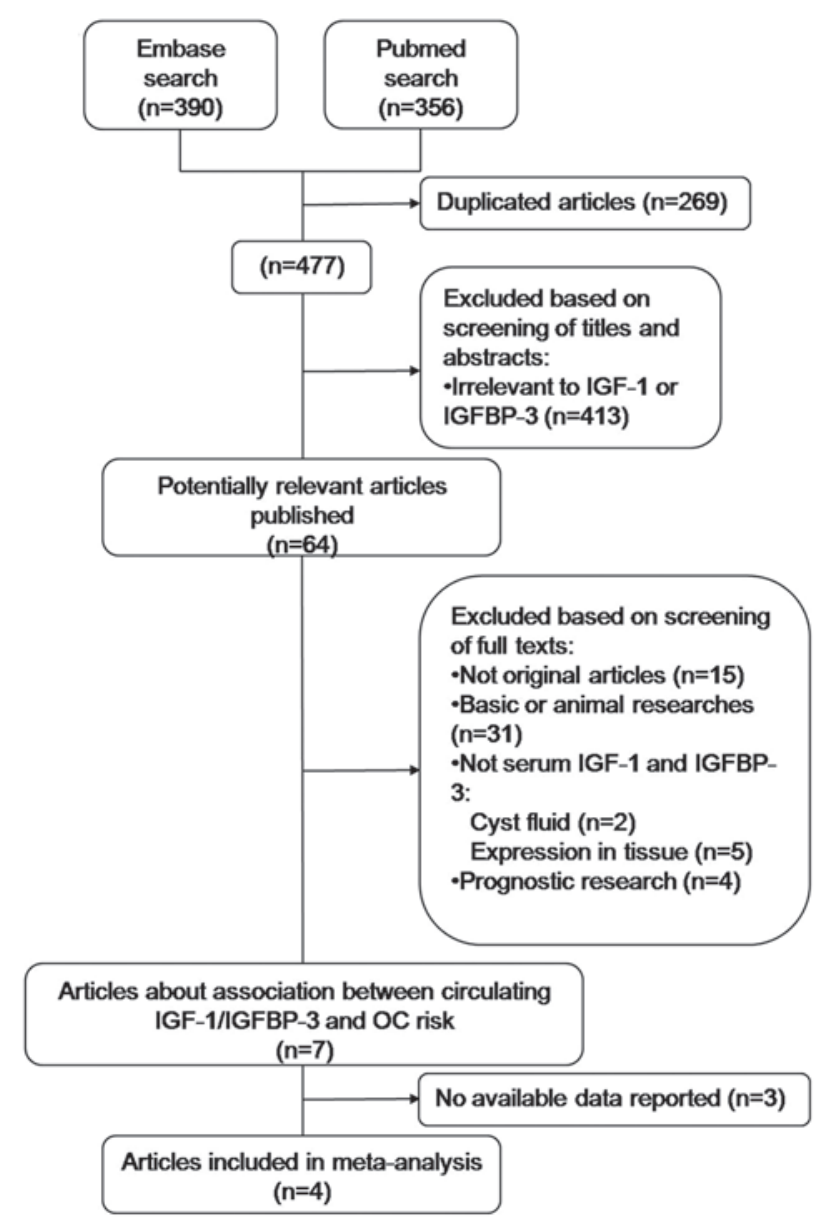

Figure 1. Flow diagram of the literature search process. IGF-1, insulin-like growth factor 1; IGFBP-3, insulin-like growth factor binding protein 3; OC, ovarian cancer

was population-based and the others were hospital-based. All three prospective studies reported analyses while excluding cases diagnosed within 1 or 2 years of blood donation. Peeters et al (10) and Lukanova et al (11) reported exclusions of females currently using exogenous hormones at the time of blood donation, which was not mentioned in other studies. Categories of IGF-1/IGFBP-3 levels were calculated on the basis of the distribution of controls $(10,19)$ or the distribution of cases and controls $(11,12)$. Intra-assay coefficients of variation were reported as generally low in all the studies. All the studies adjusted crude ORs with $\geq 3$ confounders. ORs of three studies were further adjusted; IGF-1 models for levels of IGFBP-3, and IGFBP-3 models for levels of IGF-1. One study [Dal Maso et al (19)] reported the results of free and total circulating IGF-1 levels, where the data of total IGF-1 was used. Study characteristics are demonstrated in Table I.

Associations with ovarian cancer risk. There were no statistically significant associations of circulating IGF-1 or IGFBP-3 with ovarian cancer risk when the maximally adjusted ORs for the highest verses lowest exposure levels in each study were pooled into meta-analysis [OR, 0.85 (95\% CI, 0.51-1.40) for IGF-1 and OR, 0.78 (95\% CI, 0.43-1.40) for IGFBP-3]. When participants in all the studies were analyzed as a whole, potential heterogeneity among the studies was represented in 
Table I. Study characteristics.

\begin{tabular}{|c|c|c|c|c|c|c|c|c|c|c|}
\hline $\begin{array}{l}\text { First } \\
\text { author } \\
\text { (year) }\end{array}$ & Region & $\begin{array}{l}\text { Study } \\
\text { period }\end{array}$ & $\begin{array}{l}\text { Study } \\
\text { design }\end{array}$ & $\begin{array}{l}\text { No. of } \\
\text { case/ } \\
\text { control }\end{array}$ & Matched & $\begin{array}{c}\text { IGFs } \\
\text { test }\end{array}$ & $\begin{array}{l}\text { Measure/ } \\
\text { range of } \\
\text { exposure } \\
(\mathrm{ng} / \mathrm{ml})\end{array}$ & $\begin{array}{l}\text { Adjustment } \\
\text { for covariates }\end{array}$ & $\begin{array}{l}\text { Study } \\
\text { quality }^{\mathrm{a}}\end{array}$ & (Refs.) \\
\hline $\begin{array}{l}\text { Peeters } \\
(2007)\end{array}$ & $\begin{array}{l}\text { Denmark, } \\
\text { France, Greece, } \\
\text { Germany, Italy, } \\
\text { The Netherlands, } \\
\text { Spain, UK }\end{array}$ & 1999-2003 & $\begin{array}{l}\text { Prospective } \\
\text { nested c/c }\end{array}$ & $214 / 388$ & Yes & $\begin{array}{l}\text { Serum, } \\
\text { ELISA }\end{array}$ & $\begin{array}{l}\quad<156 \\
\text { (tertfile 1) } \\
\quad \geq 216 \\
\text { (tertfile 3) }\end{array}$ & $\begin{array}{l}\text { Parity, BMI, ever use } \\
\text { of HRT or OCont } \\
\text { and fertility problems }\end{array}$ & 9 & (10) \\
\hline $\begin{array}{l}\text { Lukanova } \\
(2002)\end{array}$ & $\begin{array}{l}\text { USA, } \\
\text { Sweden, } \\
\text { Italy }\end{array}$ & $1985-2000$ & $\begin{array}{l}\text { Prospective } \\
\text { nested c/c }\end{array}$ & $132 / 263$ & Yes & $\begin{array}{l}\text { Serum/ } \\
\text { plasma, } \\
\text { IRMA, } \\
\text { blind test }\end{array}$ & Tertile & $\begin{array}{l}\text { Parity, smoking } \\
\text { status, BMI and } \\
\text { IGFs system }\end{array}$ & 8 & (11) \\
\hline $\begin{array}{l}\text { Tworoger } \\
\text { (2007) }\end{array}$ & USA & 1976-2004 & $\begin{array}{l}\text { Prospective } \\
\text { nested c/c }\end{array}$ & $222 / 599$ & Yes & $\begin{array}{l}\text { Plasma, } \\
\text { ELISA, } \\
\text { blind test }\end{array}$ & $\begin{array}{c}<139 \\
\text { (quartile 1) } \\
169 \text { to }<212 \\
\text { (quartile 3) }\end{array}$ & $\begin{array}{l}\text { Parity, ever use of } \\
\text { HRT or OCont, } \\
\text { simple hysterectomy, } \\
\text { tubal ligation, } \\
\text { physical activity, } \\
\text { age at menarche } \\
\text { and menopause, } \\
\text { IGFs system }\end{array}$ & 8 & (12) \\
\hline $\begin{array}{l}\text { Dal Maso } \\
\text { (2004) }\end{array}$ & Italy & $1999-2003$ & $\mathrm{c} / \mathrm{c}$ & $59 / 108$ & NR & $\begin{array}{l}\text { Plasma, } \\
\text { ELISA }\end{array}$ & $\begin{array}{l}\quad<103 \\
\text { (tertfile } 1) \\
\quad \geq 151 \\
\text { (tertfile } 3 \text { ) }\end{array}$ & $\begin{array}{l}\text { Parity, HRT, OCont, } \\
\text { smoking status and } \\
\text { IGFs system }\end{array}$ & 7 & (19) \\
\hline
\end{tabular}

a Study quality was assessed using the nine-star Newcastle-Ottawa scale. IGF, insulin-like growth factor; c/c, case-control study; ELISA, enzyme-linked immunosorbent assay; BMI, body mass index; HRT, hormone replacement therapy; OCont, oral contraceptive; IRMA, immunoradiometric assay; NR, not reported.

the analysis model $\left(\mathrm{P}=0.103, \mathrm{I}^{2}=51.5 \%\right.$ in the IGF-1 model; and $\mathrm{P}=0.042, \mathrm{I}^{2}=63.4 \%$ in the IGFBP-3 model) (Figs. 2 and 3 ).

In the subgroup analyses according to the age at diagnosis, the pooled ORs of IGF-1 were 1.89 (95\% CI, 0.64-5.59) for the subgroup with cases diagnosed before 55 years (tests of heterogeneity: $\left.\mathrm{P}=0.063, \mathrm{I}^{2}=63.7 \%\right)$ and $0.74(95 \% \mathrm{CI}, 0.50-1.08)$ for the subgroup with cases diagnosed at $\geq 55$ years (tests of heterogeneity: $\mathrm{P}=0.362, \mathrm{I}^{2}=0.0 \%$ ). The pooled ORs of IGFBP3 were 1.08 (95\% CI, 0.50-2.32) for the subgroup cases diagnosed before 55 years (tests of heterogeneity: $\mathrm{P}=0.209, \mathrm{I}^{2}=36.1 \%$ ) and 0.98 (95\% CI, 0.73-1.33) for the subgroup with cases diagnosed at $\geq 55$ years (tests of heterogeneity: $\mathrm{P}=0.617, \mathrm{I}^{2}=0.0 \%$ ) (Figs. 2 and 3 ).

In the meta-regression models, the residual variation due to heterogeneity was not changed by geographic regions, year of publication, sample type (serum or plasma), assays (immunoradiometric assay or ELISA), confounders (smoking status or ever use of hormones) or range of exposure levels. However, the Knapp-Hartung meta-regression model (17) reported that the heterogeneity in the meta-analysis model of IGF-1 was mainly from studies that did not exclude females using exogenous hormones at the time of blood donation (residual $\mathrm{I}^{2}=0.0 \%$ ). However, no significant variation in pooled OR and $95 \%$ CI with Knapp-Hartung modification was identified. No evidence of interactions with the above variables was found in the meta-regression analyses of the IGFBP-3 model. The results of the sensitivity analyses indicated that the significance of pooled ORs was not influenced by each individual study. The funnel plot shapes revealed no clear asymmetry. Further Egger's test (18) suggested no evidence of publication bias $(\mathrm{P}=0.404$ in IGF- 1 model and $\mathrm{P}=0.062$ in IGFBP-3 model).

Three studies reporting the exact numbers of cases and controls in each exposure category were included in the random effects dose-response meta-analysis (15). No linear association was found between circulating IGF-1/IGFBP-3 levels and ovarian cancer risk [OR, 0.39 (95\% CI, 0.13-1.13), $\mathrm{P}=0.083$ for IGF-1 and OR, 0.93 (95\% CI, 0.72-1.21), $\mathrm{P}=0.584$ for IGFBP-3]. All the analyses were repeated with unadjusted ORs and similar findings were identified.

\section{Discussion}

No significant association of circulating IGF-1/IGFBP-3 with ovarian cancer risk was indicated in the present meta-analysis or in the dose-response analysis. Potential heterogeneity was represented when regarding participants in all the studies as a whole. However, heterogeneity in the IGFBP-3 model was significantly diminished using subgroup analysis based on age at diagnosis. Furthermore, meta-regression models were conducted and it was found that inclusion of females that were using exogenous hormones at the time of blood donation in studies was the main source of heterogeneity in analysis of IGF-1. This could be explained by the complicated interactions between sex steroid hormones and the IGF system. A previous 


\begin{tabular}{|c|c|c|c|}
\hline Study, year & Case/contro & $\begin{array}{l}\text { Odds ratio } \\
\text { (95\% Cl) }\end{array}$ & Weight \\
\hline Peeters, 2007 & $214 / 388$ & $1.1(0.7-1.7)$ & 36.10 \\
\hline Lukanova, 2002 & $132 / 263$ & $1.38(0.68-2.84)$ & 24.89 \\
\hline Tworoger, 2007 & 222/599 & $0.51(0.26-1.01)$ & 26.19 \\
\hline Dal Maso, 2004 & 59/108 & $0.44(0.13-1.46)$ & 12.82 \\
\hline Overall & $627 / 1358$ & $0.85(0.51-1.40)$ & 100.0 \\
\hline \multicolumn{4}{|c|}{$\begin{array}{l}\text { Text of heterogeneity: Chi }{ }^{2}=6.19 \text { (d.f.= 3), } p=0.103 \\
p^{2}=51.5 \%, \text { Tau }^{2}=0.13\end{array}$} \\
\hline \multicolumn{4}{|l|}{ Subgroupanalysis } \\
\hline \multicolumn{4}{|l|}{ Diagnosed at age $<55$ years } \\
\hline Peeters, 2007 & $66 / 128$ & $2.40(0.90-6.40)$ & 15.09 \\
\hline Lukanova, 2002 & $41 / 81$ & $4.98(1.21-20.6)$ & 9.91 \\
\hline Tworoger, 2007 & $59 / 153$ & $0.70(0.25-1.97)$ & 14.35 \\
\hline Subtotal $\left(\mathrm{r}^{2}=63.7 \%, \mathrm{p}=0.063\right)$ & 166/362 & $1.89(0.64-5.59)$ & 39.36 \\
\hline \multicolumn{4}{|c|}{ Diagnosedat age $>$ or $=55$ years } \\
\hline Peeters, 2007 & $148 / 268$ & $0.90(0.50-1.60)$ & 21.90 \\
\hline Lukanova, 2002 & 91/181 & $0.94(0.41-2.18)$ & 17.38 \\
\hline Tworoger, 2007 & $163 / 446$ & $0.52(0.28-0.95)$ & 21.36 \\
\hline Subtotal $\left(r^{2}=1.5 \%, p=0.362\right)$ & 402/895 & $0.74(0.50-1.08)$ & 60.64 \\
\hline Overall $\left(l^{2}=60.8 \%, p=0.026\right)$ & 568/1257 & $1.07(0.82-1.85)$ & 100.0 \\
\hline
\end{tabular}
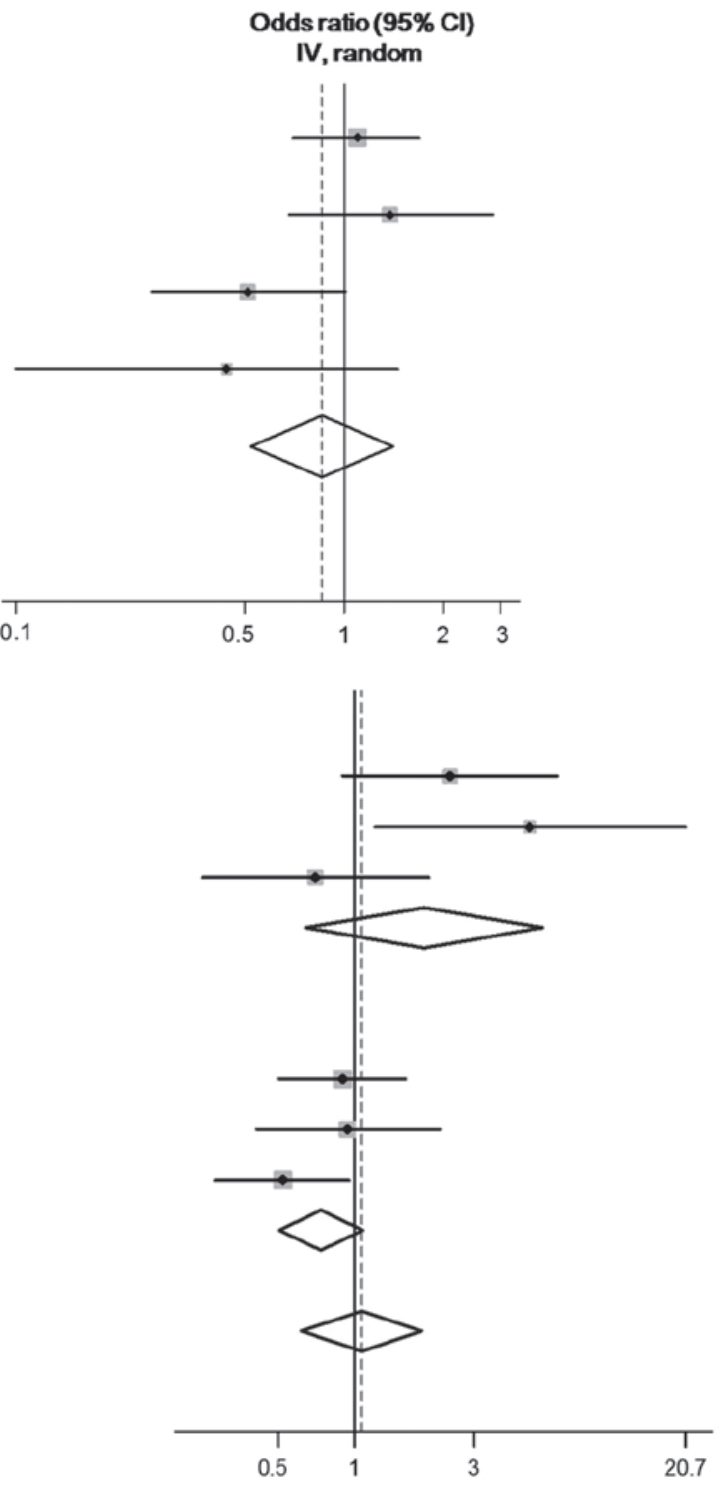

Figure 2. Maximally adjusted odds ratios for the highest verses lowest levels of circulating insulin-like growth factor 1. CI, confidence interval.

study (20) reported that exogenous hormone use may affect the peptide levels in the IGF signaling pathway, which induced the decrease of circulating IGF-1 concentration.

In all the studies reviewed in the present analysis, two prospective nested case-control studies [Peeters et al (10) and Lukanova et al (11)] addressed the hypothesis that higher circulating levels of IGF-1 increase ovarian cancer risk and suggested an association of circulating IGF-1 concentrations with ovarian cancer risk for females diagnosed before 55 years. The study by Lukanova reported a 5 -fold higher risk for the highest verses lowest exposure levels of IGF-1 in cases diagnosed at $<55$ years. However, this systemic review did not represent consistent findings in the subgroup meta-analysis.

Compared to the above two studies, an inverse association of circulating IGF-1 with ovarian cancer risk was observed in the case-control study [Dal Maso et al (19)] included, which also reported a negative association of IGFBP-3 with ovarian cancer. Considering the lower quality level in the methodology of the retrospective study, a meta-analyses was conducted while excluding this case-control study. As a result, heterogeneity in the overall analysis model of IGFBP-3 was eliminated, though no significant association with ovarian cancer or similar change in IGF-1 model was shown [OR, 0.93 (95\% CI, 0.55-1.59), $\mathrm{P}=0.096, \mathrm{I}^{2}=59.4 \%$ in the IGF-1 model; and OR, 1.03 (95\% CI, 0.74-1.44), $\mathrm{P}=0.819, \mathrm{I}^{2}=0.0 \%$ in the IGFBP-3 model]. The variation of heterogeneity in the IGFBP-3 model may be partly explained by the blood samples in the retrospective observational study not being obtained prior to the incidence of disease, which could affect the circulating IGFBP-3 levels in complicated ways.

The present meta-analysis was conducted to comprehensively and precisely evaluate the association of circulating IGF-1/IGFBP-3 with ovarian cancer, by combining the inconsistent findings of independent but similar studies. However, the meta-analyses found no sufficient evidence to confirm that circulating IGF-1/IGFBP-3 levels are associated with ovarian cancer risk. This result may be limited by the small number of current relevant studies and sample size included. In addition, as the majority of control groups were set in hospitals and health 


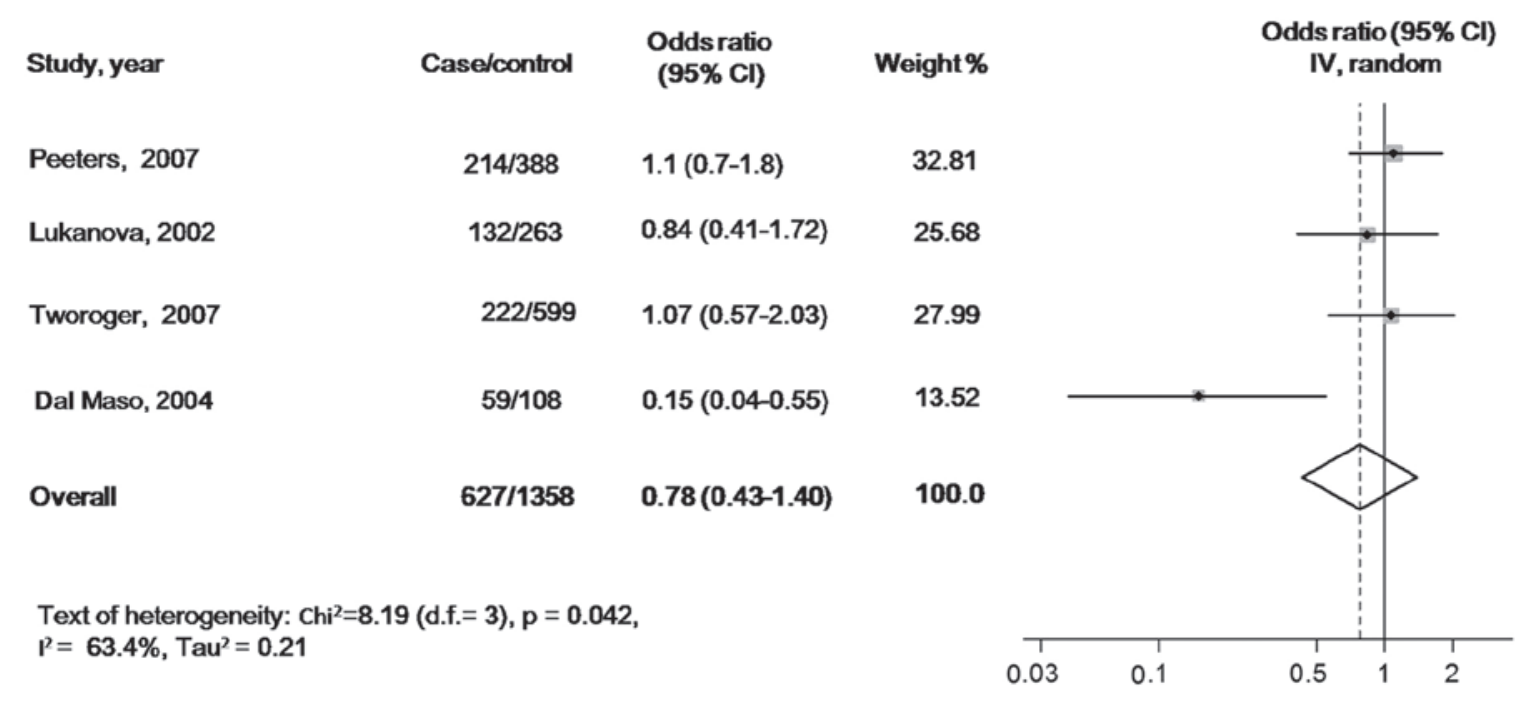

\begin{tabular}{|c|c|c|c|}
\hline \multicolumn{4}{|l|}{ Subgroupanalysis } \\
\hline \multicolumn{4}{|l|}{ Diagnosed at age $<55$ years } \\
\hline Peeters, 2007 & $66 / 127$ & $2.10(0.80-5.40)$ & 9.73 \\
\hline Lukanova, 2002 & $39 / 81$ & $0.87(0.23-3.25)$ & 5.06 \\
\hline Tworoger, 2007 & $59 / 151$ & $0.64(0.25-1.67)$ & 9.84 \\
\hline Subtotal $\left(p^{2}=36.1 \%, p=0.209\right)$ & $164 / 359$ & $1.08(0.50-2.32)$ & 24.64 \\
\hline \multicolumn{4}{|l|}{ Diagnosed at age $>$ or $=55$ years } \\
\hline Peeters, 2007 & $148 / 260$ & $1.00(0.60-1.70)$ & 32.73 \\
\hline Lukanova, 2002 & $85 / 174$ & $1.09(0.46-2.62)$ & 11.73 \\
\hline Tworoger, 2007 & $162 / 446$ & $0.86(0.50-1.46)$ & 30.91 \\
\hline Subtotal $\left(P^{2}=0.0 \%, p=0.876\right)$ & $395 / 880$ & $0.96(0.68-1.34)$ & 75.36 \\
\hline Overall $\left(l^{2}=0.0 \%, p=0.617\right)$ & $559 / 1239$ & $0.98(0.73-1.33)$ & 100.0 \\
\hline
\end{tabular}

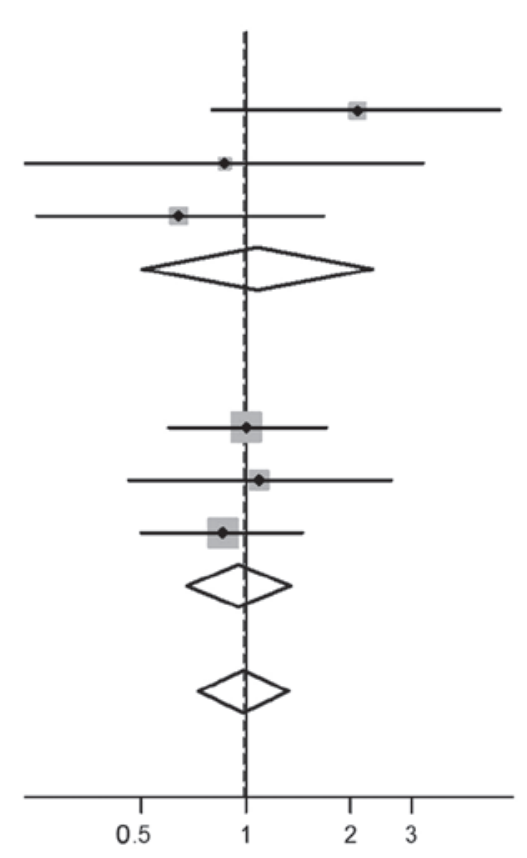

Figure 3. Maximally adjusted odds ratios for the highest verses lowest levels of circulating insulin-like growth factor binding protein 3. CI, confidence interval.

care centers, controls were not definitely free of other benign diseases that may affect the circulating levels of IGFs (21). In addition, although considerable effort was put into assessing the variation from heterogeneity and finally identifying three potential sources of heterogeneity (inclusion of females using exogenous hormones at blood donation in the IGF-1 model, and age at diagnosis and study type in the IGFBP-3 model), solving all the problems without sufficient relevant studies with available additional data on the confounders was not possible. Therefore, a more precise analysis of larger samples remains if future studies with improved quality are available.

Despite the limitations, the present meta-analysis currently represents the overall view regarding the association of circulating IGF-1/IGFBP-3 levels and ovarian cancer risk, which has not been systematically reviewed previously. Additionally, the review exhibits several important problems that should be considered in future research. Despite the importance of prospective study design and stratified analyses of age, which were already discussed in the previous studies and systematic review in associating IGF-1/IGFBP-3 with other cancers (5-9), the influence caused by the status of exogenous hormone use in participants is indicated. Even though all the studies in the review adjusted ORs with oral contraceptive use as one of covariates in logistic models, inclusion of participants currently using exogenous hormones at blood donation was supposed to significantly contribute to heterogeneity in analyses, particularly in the IGF-1 model. Thus, whether exclusion of this group of participants or subgroup set is necessary should be considered in future study design.

In conclusion, the present meta-analysis found no significant association of IGF-1/IGFBP-3 with ovarian cancer risk. However, a more precise analysis with larger sample sizes should be conducted if more studies with improved quality are available in the future. 


\section{References}

1. King ER and Wong KK: Insulin-like growth factor: current concepts and new developments in cancer therapy. Recent Patents Anticancer Drug Discov 7: 14-30, 2012.

2. Adams TE, Epa VC, Garrett TP and Ward CW: Structure and function of the type 1 insulin-like growth factor receptor. Cell Mol Life Sci 57: 1050-1093, 2000

3. Jones JI and Clemmons DR: Insulin-like growth factors and their binding proteins: biological actions. Endocr Rev 16: 3-34, 1995.

4. Khandwala HM, McCutcheon IE, Flyvbjerg A and Friend KE: The effects of insulin-like growth factors on tumorigenesis and neoplastic growth. Endocr Rev 21: 215-244, 2000.

5. Renehan AG, Zwahlen M, Minder C, O'Dwyer ST, Shalet SM and Egger M: Insulin-like growth factor (IGF)-I, IGF binding protein-3 and cancer risk: systematic review, and meta-regression analysis. Lancet 363: 1346-1353, 2004.

6. Toniolo P, Bruning PF, Akhmedkhanov A, et al: Serum insulin-like growth factor-I and breast cancer. Int J Cancer 88: 828-832, 2000.

7. Stattin P, Bylund A, Rinaldi S, et al: Plasma insulin-like growth factor-I, insulin-like growth factor-binding proteins, and prostate cancer risk: a prospective study. J Natl Cancer Inst 92: 1910-1917, 2000.

8. Chan JM, Stampfer MJ, Giovannucci E, et al: Plasma insulin-like growth factor-I and prostate cancer risk: a prospective study. Science 279: 563-566, 1998.

9. Palmqvist R, Hallmans G, Rinaldi S, et al: Plasma insulin-like growth factor 1 , insulin-like growth factor binding protein 3 , and risk of colorectal cancer: a prospective study in northern Sweden. Gut 50: 642-646, 2002.

10. Peeters PH, Lukanova A, Allen N, et al: Serum IGF-I, its major binding protein (IGFBP-3) and epithelial ovarian cancer risk: the European Prospective Investigation into Cancer and Nutrition (EPIC). Endocr Relat Cancer 14: 81-90, 2007.

11. Lukanova A, Lundin E, Toniolo P, et al: Circulating levels of insulin-like growth factor-I and risk of ovarian cancer. Int J Cancer 101: 549-554, 2002.

12. Tworoger SS, Lee IM, Buring JE, Pollak MN and Hankinson SE: Insulin-like growth factors and ovarian cancer risk: a nested case-control study in three cohorts. Cancer Epidemiol Biomarkers Prev 16: 1691-1695, 2007.

13. Stroup DF, Berlin JA, Morton SC, et al: Meta-analysis of observational studies in epidemiology: a proposal for reporting. Meta-analysis Of Observational Studies in Epidemiology (MOOSE) group. JAMA 283: 2008-2012, 2000.

14. Stang A: Critical evaluation of the Newcastle-Ottawa scale for the assessment of the quality of nonrandomized studies in meta-analyses. Eur J Epidemiol 25: 603-605, 2010.
15. DerSimonian R and Laird N: Meta-analysis in clinical trials. Control Clin Trials 7: 177-188, 1986.

16. Greenland S and Longnecker MP: Methods for trend estimation from summarized dose-response data, with applications to meta-analysis. Am J Epidemiol 135: 1301-1309, 1992.

17. Thompson SG and Sharp SJ: Explaining heterogeneity in meta-analysis: a comparison of methods. Stat Med 18: 2693-2708, 1999.

18. Egger M, Davey Smith G, Schneider M and Minder C: Bias in meta-analysis detected by a simple, graphical test. BMJ 315: 629-634, 1997.

19. Dal Maso L, Augustin LS, Franceschi S, et al: Association between components of the insulin-like growth factor system and epithelial ovarian cancer risk. Oncology 67: 225-230, 2004.

20. Fox EM, Miller TW, Balko JM, et al: A kinome-wide screen identifies the insulin/IGF-I receptor pathway as a mechanism of escape from hormone dependence in breast cancer. Cancer Res 71: 6773-6784, 2011.

21. Suikkari AM, Tiitinen A, Stenman UH, Seppala M and Laatikainen T: Oral contraceptives increase insulin-like growth factor binding protein-1 concentration in women with polycystic ovarian disease. Fertil Steril 55: 895-899, 1991.

22. Tas F, Karabulut S, Serilmez M, Ciftci R and Duranyildiz D: Clinical significance of serum insulin-like growth factor-1 (IGF-1) and insulin-like growth factor binding protein-3 (IGFBP-3) in patients with epithelial ovarian cancer. Tumour Biol 35: 3125-3132, 2014.

23. Dursun P, Gultekin M and Esin S: Preoperative serum IGF-1 and IGFBP-3 levels in patients with ovarian carcinoma: preliminary results. Int J Gynecol Cancer 14: 105-106, 2004.

24. Serin IS, Tanriverdi F, Yilmaz MO, Ozcelik B and Unluhizarci K: Serum insulin-like growth factor (IGF)-I, IGF binding protein (IGFBP)-3, leptin concentrations and insulin resistance in benign and malignant epithelial ovarian tumors in postmenopausal women. Gynecol Endocrinol 24: 117-121, 2008.

25. el-Roeiy A, Chen X, Roberts VJ, et al: Expression of the genes encoding the insulin-like growth factors (IGF-I and II), the IGF and insulin receptors, and IGF-binding proteins-1-6 and the localization of their gene products in normal and polycystic ovary syndrome ovaries. J Clin Endocrinol Metab 78: 1488-1496, 1994.

26. Flyvbjerg A, Mogensen O, Mogensen B and Nielsen OS: Elevated serum insulin-like growth factor-binding protein 2 (IGFBP-2) and decreased IGFBP-3 in epithelial ovarian cancer: correlation with cancer antigen 125 and tumor-associated trypsin inhibitor. J Clin Endocrinol Metab 82: 2308-2313, 1997. 